\title{
SISTEM MONITORING KANOPI PINTAR SECARA REAL-TIME BERBASIS IOT
}

\author{
Abdul Refli Gunawan ${ }^{1}$, Aris Gunaryati ${ }^{2}$, Ucuk Darusalam ${ }^{3}$ \\ Jurusan Informatika Universitas Nasional \\ abdul.refli@gmail.com ${ }^{1}$, arisgunaryati@civitas.unas.ac.id ${ }^{2}$, ucuk.darusalam@civitas.unas.ac.id ${ }^{3}$
}

Submitted December14, 2020; Revised December 21, 2020; Accepted December 25, 2020

\begin{abstract}
Abstrak
Penjemuran pakaian yang dilakukan sehari-hari terkadang mengalami kendala saat turun hujan. Hal ini membuat pakaian menjadi basah kembali. Sistem kanopi pintar yang dapat medeteksi hujan dibutuhkan untuk memaksimalkan pekerjaan sehari-hari. Pada penelitian ini dirancang sistem monitoring kanopi pintar secara real-time berbasis Internet Of Things dan cloud platform ThingSpeak yang dapat memantau status kanopi dan curah hujan. Sistem ini menggunakan sensor air untuk mendeteksi air hujan. Nilai maksimal dari sensor tersebut adalah 1024. Pemorosesan data menggunakan NodeMCU yang berfungsi sebagai media pemrosessan dan pengiriman data. Dari penelitan yang dilakukan, rata - rata waktu yang diterima oleh ThingSpeak adalah 1 detik. Sistem ini berbasis web, sehingga pemantauan mudah dilakukan. Penentuan tindakan kanopi pintar ditentukan menggunakan metode fuzzy logic dengan ketepatan dalam penentuan tindakan sebesar $100 \%$.
\end{abstract}

Kata Kunci : Kanopi Pintar, Internet Of Things, Monitoring, Realtime

\begin{abstract}
Daily drying of clothes sometimes has problems when it rains. This makes the clothes wet again. A smart canopy system that can detect rain is needed to maximize daily work. In this study, a real-time smart canopy monitoring system was designed based on the Internet of Things and the ThingSpeak cloud platform that can monitor the status of the canopy and rainfall. This system uses a water sensor to detect rainwater. The maximum value of the sensor is 1024. Data processing uses NodeMCU which functions as a medium for processing and sending data. From the research conducted, the average time received by ThingSpeak is 1 second. The system is web-based, so monitoring is easy. Determination of the smart canopy action is determined using the fuzzy logic method with accuracy in determining the action of $100 \%$.
\end{abstract}

Key Words : Smart canopy, Internet Of Things, Monitoring, Realtime

\section{PENDAHULUAN}

Menjemur pakaian sudah pasti memerlukan cahaya matahari dan musuh terbesar saat menjemur pakaian adalah hujan, Menjemur pakaian adalah salah satu kegiatan yang sering dilakukan di dalam kehidupan rumah tangga, pada saat terjadi hujan dan tidak dapat mengangkat jemuran secara cepat maka pakaian menjadi basah.

Berdasarkan teori diatas peneliti mengusulkan tentang sistem monitoring kanopi pintar yang dapat mangirim data secara realtime ke platform ThingSpeak, data yang dilihat dari ThingSpeak dapat mengetahui sedang terjadi hujan atau tidak, dan jika terjadi hujan kanopi pintar ini otomatis menutupi pakaian yang sedang di jemur sehingga tidak basah.

Berdasarkan penelitian "Prototype Jemuran Otomatis Menggunakan Sensor Air dan Sensor Ldr Berbasis Mikrokontroler Arduino Uno Dengan Metode Flc" dibuat sebuah jemuran yang akan bergerak jika sensor air dan sensor Ldr mendeteksi hujan tetapi cara ini kurang efektif dikarenakan harus memiliki lahan yang sedikit lebih luas untuk menarik pakaian dari tempat terbuka ketempat tertutup [1]. 
Dan berdasarkan penelitian "Prototype Sistem Kemanan Buka Tutup Atap Jemuran Otomatis Menggunakan Sensor Air dan Light Dependent Resistor (LDR) Berbasis Arduino" sudah dapat meminimalisir pemakaian tempat namun belum berbasis web atau android [2].

Berdasarkan penelitian terdahulu peneliti memberikan solusi dan keterbaharuan dalam sistem yang sudah dibuat, yaitu pembuatan kanopi pintar yang sudah terintegerasi platform ThingSpeak yang dapat memantau terjadi hujan secara realtime. Sistem ini mengaplikasikan algoritma fuzzy logic untuk penentu tindakan yang harus dilakukan motor servo untuk menggerakan kanopi ke tempat jemuran sehingga pakaian tidak basah terkena air hujan. Karena hujan di Indonesia ini tidak selalu dapat diprediksi akan terjadinya hujan, maka dibuat penakar hujan tipe bucket untuk mencatat dan mendata seberapa banyak curah hujan yang terjadi [3].

Perubahan iklim di Indonesia ini sangat sulit di tebak maka sudah banyak teknologi yang dikembangkan terkait masalah hujan ini, disaat hujan terjadi sangat sering dibarengi dengan cuaca gelap, hal ini yang mengakibatkan tercipta kanopi otomatis sehingga disaat cuaca gelap kanopi tersebut akan tertutup [4].

Rancangan kanopi pintar ini akan berkembang menggunakan sensor air berbasis mikrokontroler NodeMCU, rancangan ini akan berfungsi saat sensor air mendeteksi banyaknya air yang mengenai sensor, apabila sudah melebihi batas maka sensor akan mengaktifkan penggerak yang menggerakan kanopi sehingga jemuran tidak akan terkena air hujan dan jemuran tetap kering.

Kanopi pintar ini juga dapat dimonitoring dengan web ThingSpeak secara RealTime, yang berarti monitoring ini sangat berfungsi untuk melihat keadaan kanopi pintar sedang dalam keadaan terbuka atau tertutup dan untuk yang tidak berada dalam rumah atau sedang berpergian juga tetap dapat memonitoring kanopi pintar ini karena kanopi pintar ini sudah berbasis internet.

\section{METODE PENELITIAN}

Kanopi pintar dalam penelitian ini menggunakan sensor air untuk mendeteksi nilai air yang mengenai sensor. Data dari sensor ini akan di peroses oleh mikrokontroler NodeMCU untuk mendeteksi berapa banyak nilai air yang mengenai sensor, data nilai air tersebut di kirim dan dicatat di Cloud Platform (ThinkSpeak). Karena pada penelitian ini menerapkan fuzzy logic untuk penentuan status kanopi berdasarkan data yang diterima dari sensor air untuk melakukan tindakan terhadap motor servo .

\section{A. Analisis Kebutuhan Sistem}

Analisis kebutuhan sistem ini perlu dilakukan untuk mengetahui apa saja yang akan digunakan dalam membangun sistem kanopi pintar. Berikut adalah kebutuhan sistem yang diperlukan :

1. Perangkat Keras

- NodeMCU

- Sensor Air

- Motor Servo

- Papan ProtoBoard

- Power Supply

2. Perangkat Lunak

- Sistem Operasi (Windows 10)

- Arduino IDE 


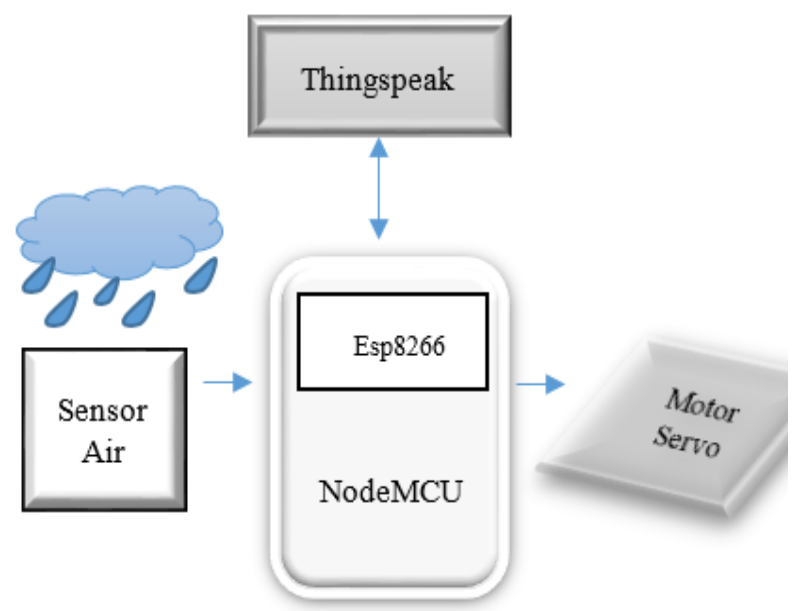

Gambar 1. Rancangan Sistem Kanopi Pintar

\section{B. Rancangan Sistem Kanopi Pintar} Rancangan sistem pada gambar 1 mempunyai fungsi masing-masing setiap bloknya :

1. Blok Sensor air yang berfungsi sebagai inputan pin analog dari board NodeMCU untuk mendeteksi air hujan yang jatuh dipermukaan panel sensor air dan merubah besaran fisik air menjadi besaran listrik, semakin sedikit air hujan yang menyentuh panel sensor maka hambatannya akan semakin besar dan sebaliknya, maksimal hambatan dalam sensor air yang digunakan adalah 1024.

2. Blok NodeMCU yang berfungsi untuk menyimpan program pada mikrokontroler untuk dapat membaca input yang dikirim oleh sensor air, memproses input tersebut dan kemudian menghasilkan output sesuai yang diinginkan. Jadi mikrokontroler bertugas sebagai 'otak' yang mengendalikan input, proses dan output sebuah rangkaian elektronik [5]. Didalam NodeMCU juga terdapat chip ESP8266 yang dimana chip ini berfungsi sebagai penghubung antara board NodeMCU dengan Cloud Platform
(ThinkSpeak). Karena ESP8266 ini mempunyai jaringan $\mathrm{WiFi}$ yang dapat diatur dengan mudah.

3. Blok motor servo berfungsi sebagai output dari board NodeMCU, motor servo ini berfungi juga sebagai komponen penggerak rangkaian berdasarkan data yang diterima dari board NodeMCU dan berasal dari sensor air [6].

4. ThinkSpeak berfungsi untuk menyimpan dan mengambil data dari sensor air melalui internet atau jaringan area lokal [7], dari data yang diterima dapat dilihat untuk kelanjutan dari kanopi pintar tersebut. Didalam PlatForm ini diberi data diagram nilai sensor air yang dapat dilihat dimana saja dan kapan saja, tentu saja ini sangat membantu untuk mengetahui cuaca disekitar rumah sedang turun hujan atau tidak.

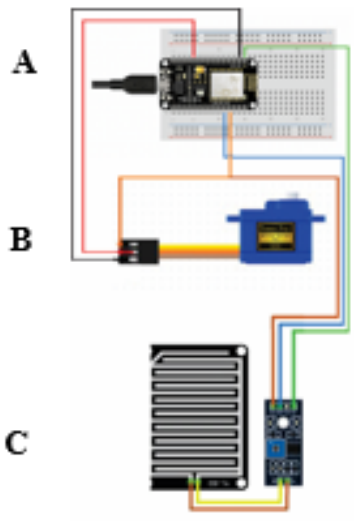

\section{Gambar 2. Skema Rangkaian Kanopi Pintar}

Pada perancangan sistem ini pusat controlnya terdapat pada board NodeMCU yang terdapat pada gambar 3 bagian A. Karena didalam NodeMCU terdapat chip ESP8266 yang memiliki jaringan internet supaya dapat mengirimkan data yang diperoleh dari sensor air ke Cloud Platform (ThingSpeak) [8]. Sensor air dapat dilihat 
pada gambar 3 bagian $\mathrm{C}$, sensor air ini mempunyai nilai maksimum sensor yaitu 1024, maka setiap nilai air yang mengenai sensor akan dikirim ke NodeMCU dan diteruskan ke motor servo pada gambar 3 bagian B.

Cara kerja dari sistem kanopi pintar ini adalah dengan cara mengambil data air yang dapat dari sensor air, dari data yang dihasilkan akan dibuat perbandingan sesuai dengan program pada mikrokontroller NodeMCU dan data tersebut dikirim ke ThingSpeak. Data yang telah dibandingkan dengan program dapat ditentukan cuaca disekitar turun hujan atau tidak. Dalam program yang disudah dibuat apabila nilai air melebihi batas (500) maka motor servo akan bergerak $180^{\circ}$ untuk menggerakkan kanopi pintar sehingga ruang terbuka akan tertutup kanopi pintar dan tidak terkena air hujan. Tetapi apabila nilai air tidak melebihi batas maka motor servo tidak bergerak dan kanopi otomatis tidak berjalan. Flowchart pada sistem pengaturan kanopi pintar ini dapat dilihat pada gambar 3 .

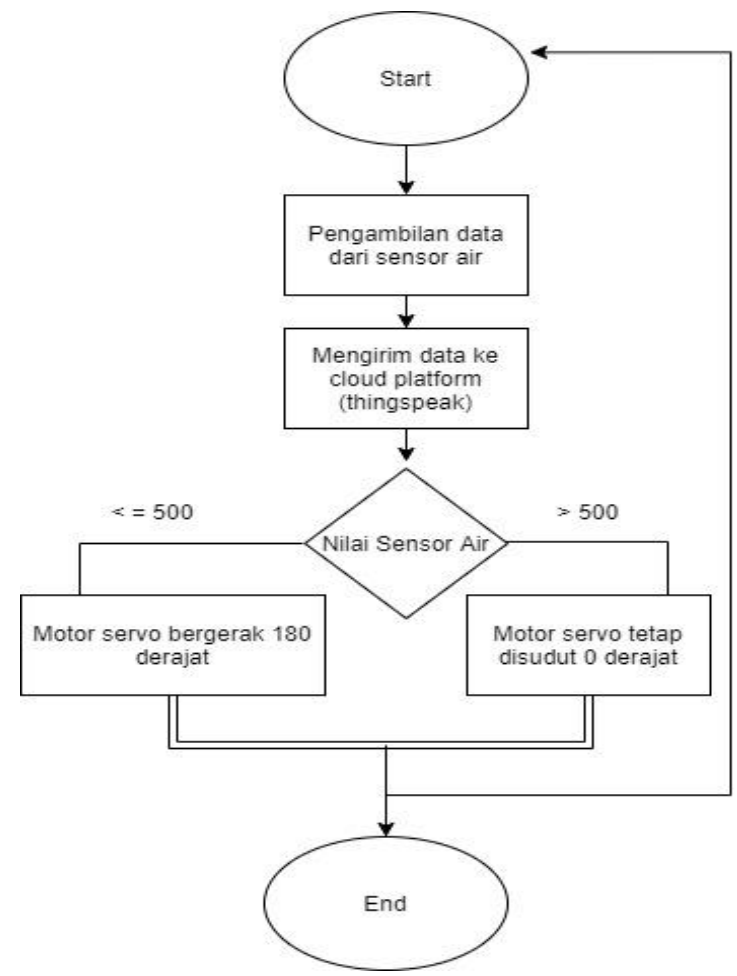

Gambar 3. Flowchart Sistem Kanopi Pintar
Pada pengujian ini dibutuhkan jaringan internet untuk menghubungkan antara ESP8266 dengan Cloud Platform Thingspeak. Untuk menghubungkannya menggunakan Arduino IDE dengan menggunakan bahasa $\mathrm{C}$ dan $\mathrm{C}++$, Didalam Arduino IDE harus menambahkan library dan menginisial WiFi yang digunakannya, kemudian memasukkan alamat IP web ThingSpeak beserta dengan API Keys Channels yang sudah dibuat sebelumnya, seperti pada gambar 4. Hubungan antara ESP8266 dengan Cloud Platform Thingspeak befungsi untuk mengirim data nilai sensor air yang diterima oleh sensor air dan data tersebut diteruskan oleh ESP8266 ke dalam Cloud Platform Thingspeak untuk dimonitoring.

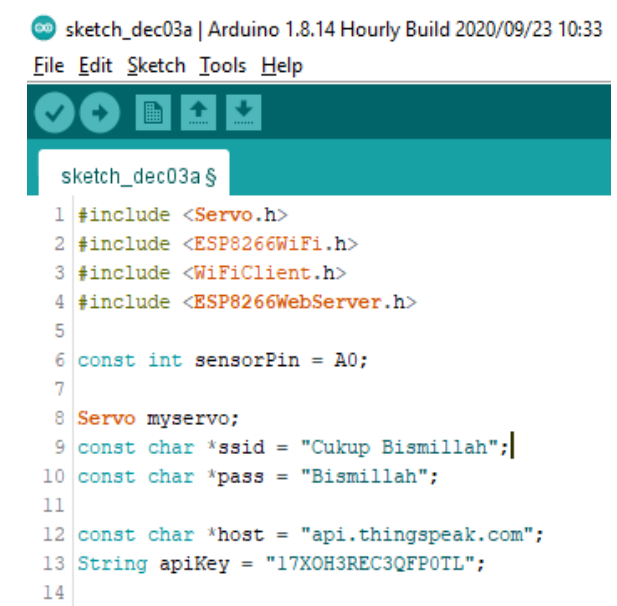

\section{Gambar 4. Menghubungkan ESP8266 dengan ThingSpeak}

\section{HASIL DAN PEMBAHASAN}

Hasil dan pembahasan ini dilakukan bertujuan untuk mengetahui bahwa kanopi pintar ini dapat membantu permasalahan yang ada. Uji coba sudah dilakukan dengan cara memulai dengan meneteskan beberapa air kedalam sensor air, untuk mempermudah perhitungan dalam uji coba maka dibuatkan dirumus sebagai berikut: 100- $\left(\frac{\text { sensor }}{1024} x 100\right)$

Berikut uji coba dari Sistem Monitoring Kanopi Pintar Secara Realtime berbasis IOT : 


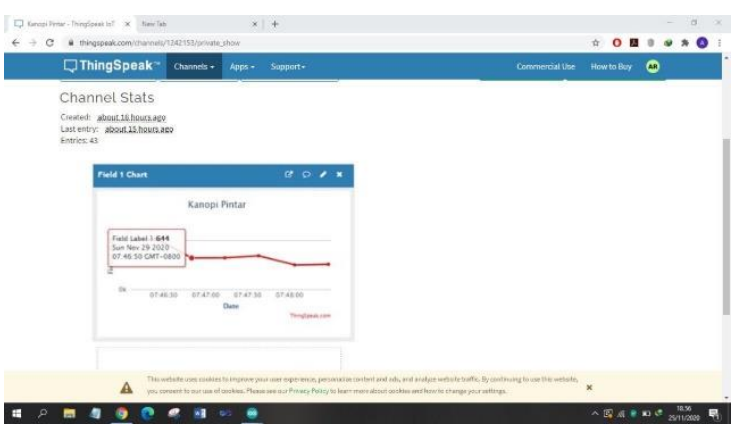

Gambar 5. Uji Coba Pertama

Diuji coba pertama ini mendapatkan nilai sensor air 644, dalam nilai ini berarti kanopi pintar masih dalam keadaan terbuka.

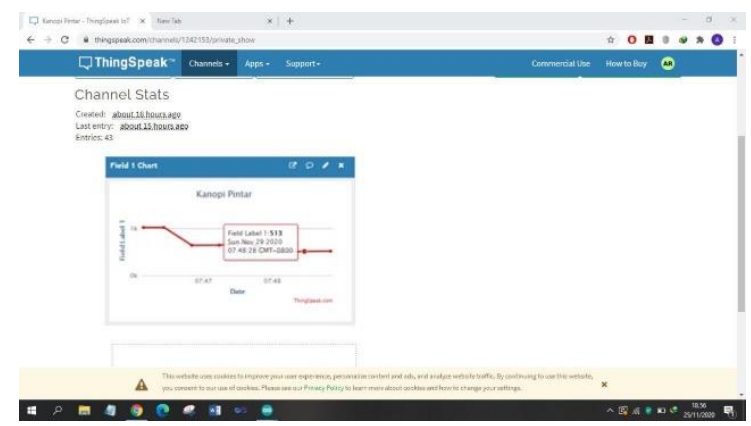

Gambar 6. Uji Coba Kedua

Pada uji coba kedua ini mendapatkan hasil nilai sensor air diangka 513 yang dimana kanopi pintar sudah bergerak menutup ruang terbuka, berdasarkan program yang sudah dibuat nilai sensor air $<=500$ maka kanopi pintar akan tertutup.

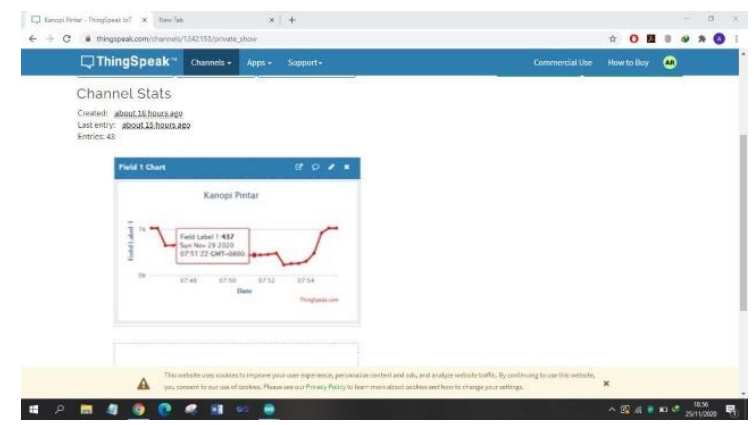

Gambar 7. Uji Coba Ketiga
Dalam uji coba ketiga ini nilai sensor air menunjukkan 437 maka kanopi pintar masih dalam keadaan tertutup.

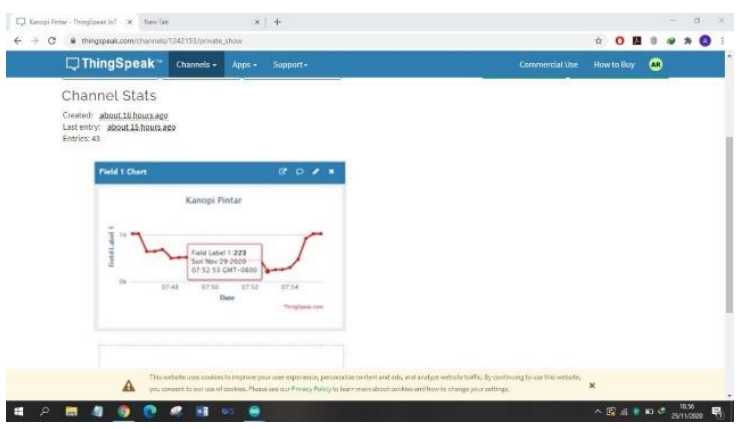

Gambar 8. Uji Coba Keempat

Diuji coba keempat ini nilai sensor air bernilai 223 yang dimana menunjukkan hujan semakin deras dan air hujan semakin mengenai sensor air maka kanopi akan tetap tertutup.

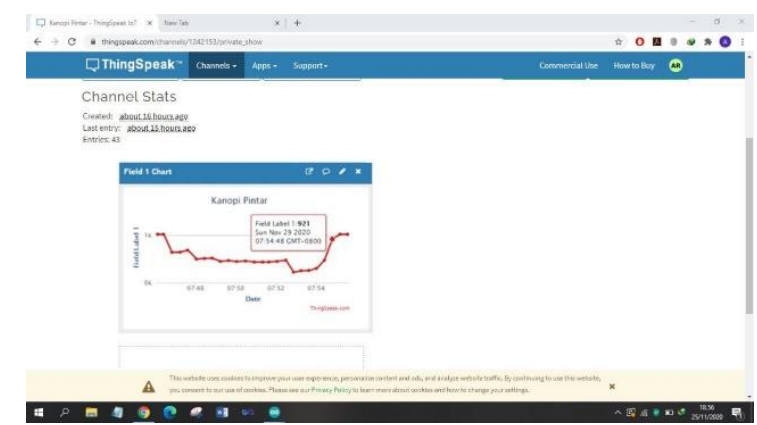

Gambar 9. Uji Coba Kelima

Dapat dilihat pada gambar nilai sensor air bernilai 921 yang berarti kanopi pintar sudah terbuka dan hujan sudah mulai reda.

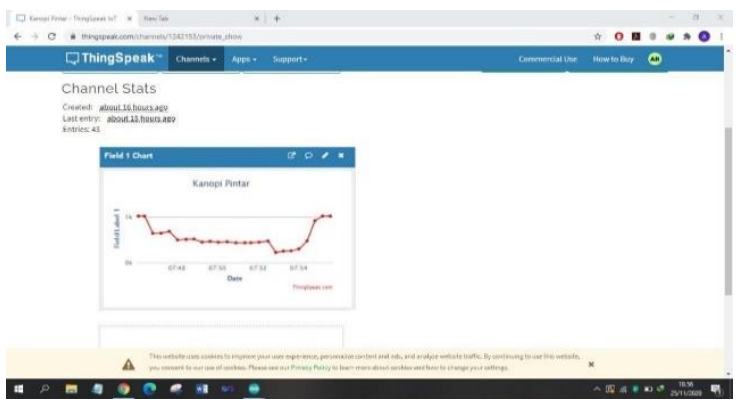

Gambar 10. Hasil Uji Coba Keseluruhan 
Dapat dilihat pada gambar 10 yang merupakan hasil keseluruhan uji coba yang sudah dilakukan mulai dari sensor air kering atau tidak terkena air kemudian basah terkena air hujan dan kering kembali.

Berdasarkan data yang didapatkan saat uji coba lalu data tersebut dihitung dengan rumus $\quad 100-\left(\frac{\text { sensor }}{1024} \times 100\right)$ dan mendapatkan hasil bernilai $37,10 \%$, $49,90 \%, 57,32 \% 78,22 \%$, dan $10,5 \%$ maka dapat dikirakan bahwa terjadinya hujan adalah $46,51 \%$, sesuai dengan tabel 1 .

Tabel 1. Hasil Uji Coba

\begin{tabular}{cccc}
\hline No & $\begin{array}{c}\text { Nilai Sensor } \\
\text { Air }\end{array}$ & Presentase & $\begin{array}{c}\text { Status } \\
\text { Kanopi }\end{array}$ \\
\hline 1 & 644 & $37,10 \%$ & Terbuka \\
2 & 513 & $49,90 \%$ & Terbuka \\
3 & 437 & $57,32 \%$ & Tertutup \\
4 & 223 & $78,22 \%$ & Tertutup \\
5 & 921 & $10,5 \%$ & Terbuka \\
\hline
\end{tabular}

\section{SIMPULAN}

Berdasarkan kesimpulan pembahasan Sistem Monitoring Kanopi Pintar Secara Realtime berbasis IOT, penggunaan sistem ini sudah sangat berguna dan membantu ibu rumah tangga dan anak kost dalam menghadapi jemuran yang ditinggal khawatir menjadi basah akibat air hujan yang tidak menentu itu, karena sistem ini sudah dapat dimonitoring juga dengan web sehingga dimanapun dan kapanpun dapat melihat status kanopi pintar ini secara Real Time. Selain itu ketepatan Kanopi pintar ini dalam mendeteksi curah hujan sangat tinggi, akan tetapi kanopi pintar ini memiliki batas maksimal sensor air yaitu bernilai 1024. Waktu pengiriman data ke Cloud Platform (ThingSpeak) ini relatif cepat terhitung kurang dari 1 detik. Dan dari hasil uji coba yang sudah dilakukan mendapatkan hasil curah hujan $46,51 \%$.

Namun kanopi pintar ini membutuhkan daya listrik dan internet maka apabila listrik padam maka kanopi pintar tidak dapat bekerja, maka sebaiknya mempunyai cadangan energi listrik seperti genset untuk dapat membuat kanopi pintar ini terus berfungsi walaupun sedang dalam keadaan listrik padam

\section{DAFTAR PUSTAKA}

[1] N. A. Harahap, "Perancangan Prototype Jemuran Otomatis Menggunakan Sensor Air dan Sensor Ldr Berbasis Mikrokontroler Arduino Uno Dengan Metode Flc," Media Inform. Budidarma, vol. 2 (1), no. ISSN. 2548-8368, 2018.

[2] A. D. Darusman, M. Dahlan and F. S. Hilyana, "Rancang Bangun Prototype Alat Jemur Pakaian Otomatis Berbasis Arduino Uno," J.Sismestris, vol. 9 (1), no. ISSN. 2252-4983, 2018.

[3] R. G. Permana, E. Rahmawati, and Dzulkiflih, "Perancangan dan Pengujian Penakar Hujan Tipe Tipping Bucket Dengan Sensor Photo-Interrupter Berbasis Arduino," J.Inovasi Fis. Indones., vol. 4 (3), no. ISSN. 2302-4216, 2015.

[4] S. M. Subagio, R. T. Sudiarto, T. Cirebon K. Air, S. Uno A, "Prototype Sistem Kemanan Buka Tutup Atap Jemuran Otomatis Menggunakan Sensor Air Dan Light Dependent Resistor ( Ldr )," vol. 8(2), pp. 161-172, 2018.

[5] R. T. Subagio, Kusnadi, and T. Sudiarto, "Prototype Sistem Kemanan Buka Tutup Atap Jemuran Otomatis Menggunakan Sensor Air dan Light Dependent Resistor (LDR) Berasis Arduino," J. Digit, vol. 8 (2), no. ISSN. 2088-589x, 2018 . 
[6] Benyezza, M. Bouhedda, and K.

[8] Mufida Elly, S, Nurajizah, and A. Djellout, "Smart Irrigation System Based Thingspeak andArduino," Int. Conf. Appl. Smart Sist, no. doi: 97815386-6866-5, 2018.

[7] S. Pasha, "ThingSpeak based sensing and monitoring system for IoT with Matlab Analysis," Int. J. New Technol. Res., vol. 2 (6), no. ISSN: 2454-4116, 2016. Abas, "Pengendali Atap Jemuran Otomatis dengan Sensor Cahaya Berbasiskan Mikrokontroler Atmega16," Konf. Nas. Ilmu Sos. dan Teknol., no. ISBN. 978-60261242-1-0, 2013. 